\title{
Are fuel additives a viable contrail mitigation option?
}

\author{
Klaus Gierens* \\ Institut für Physik der Atmosphäre, Deutsches Zentrum für Luft- und Raumfahrt, Oberpfaffenhofen, Germany
}

Received 8 January 2007; received in revised form 9 March 2007; accepted 13 March 2007

\begin{abstract}
Fuel additives have been proposed as a potential mitigation option for contrails. They could change the thermodynamic conditions necessary for contrail formation in a way that makes contrail formation more difficult than with standard kerosene fuel. Here I show how additives could affect contrail formation, and I conclude that fuel additives are not a useful way to avoid contrails.
\end{abstract}

(C) 2007 Elsevier Ltd. All rights reserved.

Keywords: Aviation; Contrails; Fuel additives; Alternative fuels; Mitigation

\section{Introduction}

Contrails and contrail cirrus are currently thought to have the greatest share in aviation's impact on the radiative forcing of the atmosphere and on climate change (Mannstein and Schumann, 2005; Sausen et al., 2005). Demand for air transportation is expected to increase with rates of about 5\% per annum. Consequently, a significant increase in contrail coverage has been predicted for the future (Gierens et al., 1999; Marquart et al., 2003), and it is necessary to develop strategies to avoid contrails or to mitigate the problem. Potential options include:

- Hard operational measures (e.g. flying constantly at lower altitudes (Fichter et al., 2004; Noland et al., 2004; Williams et al., 2002; Williams and Noland, 2005); in the mid-latitudes flying slightly higher is an option due to the higher dryness of

${ }^{*}$ Tel.: + 498153282541 ; fax: + 498153281841 .

E-mail address: klaus.gierens@dlr.de. the extratropical lowermost stratosphere which reduces contrail persistence (Schumann, 2005);

- Flexible operational measures (Mannstein et al., 2005);

- Shifting flight times to daylight hours (Stuber et al., 2006);

- Technical measures, including the use of alternative fuels (e.g. liquid hydrogen (Ponater et al., 2006)) or kerosene with additives.

The use of alternative fuels such as liquid hydrogen offers a mitigation potential for the contrail problem, because contrail optical properties and formation conditions change (Marquart et al., 2005; Ström and Gierens, 2002). However, a large fleet of hydrogen propelled aircraft (cryoplanes) will only become available in the far future. This warrants studies of contrail mitigation options for the current or near future fleet.

Another technical measure for contrail suppression is kerosene fuel additives. The idea is that such additives could be used to change contrail formation conditions in a way to make contrail formation 
less probable. (It should be stressed that such an additive is currently not available.) This idea has been discussed on a workshop in the framework of the European Network of Excellence Environmentally Compatible Air Transport System (ECATS). The goal of the workshop was to bring together aeroengine engineering and atmospheric science from within the ECATS partnership in order to exchange ideas related to engine emissions, aerosol ageing during plume dispersion, and possible effects on cirrus clouds. The present study results from these discussions and is, inter alia, intended as information provided by an atmospheric scientist to the engineers in ECATS. ECATS and a similar network in the United States (Partnership for AiR Transportation Noise and Emissions Reduction (PARTNER)) have been established with the main objective to meet the environmental challenge of aviation growth by bringing together atmospheric science, aeronautical engineering, and air traffic management, to combine their capabilities in order to develop and realise strategies for a sustainable air transportation system.

It is the goal of the present investigation to find out whether fuel additives are indeed a viable contrail mitigation option. To this end, we first discuss the potential implications of fuel additives in the light of the criterion usually employed to predict the onset of contrail formation based on thermodynamic principles, the Schmidt-Appleman criterion $(\mathrm{SAc})$.

\section{The SAc}

A complete derivation of the SAc can be found in Schumann (1996); it will not be repeated here. During the isobaric mixture of the hot and moist exhaust gases with the cold ambient air, a state of water saturation must be reached for a contrail to form. The mixing process is characterised by a parameter $G$,

$G=\frac{\mathrm{EI}_{\mathrm{H}_{2} \mathrm{O}} c_{p} p}{\varepsilon Q(1-\eta)}$,

where $\varepsilon$ is the ratio of molar masses of water and dry air $(0.622), c_{p} \approx 1004 \mathrm{~J}(\mathrm{~kg} \mathrm{~K})^{-1}$ is the isobaric heat capacity of air, and $p$ is ambient pressure. $G$ (units: $\mathrm{Pa} \mathrm{K}{ }^{-1}$ ) depends on fuel characteristics (emission index of water vapour, $\mathrm{EI}_{\mathrm{H}_{2} \mathrm{O}}=1.25 \mathrm{~kg}$ per $\mathrm{kg}$ of kerosene burnt; chemical heat content of the fuel, $Q=43 \mathrm{MJ}$ per $\mathrm{kg}$ of kerosene), and on the overall propulsion efficiency $\eta$ of aircraft. Modern airliners have approximately $\eta=0.35$. Alternative fuels can have significantly different values of $\mathrm{EI}_{\mathrm{H}_{2} \mathrm{O}}, Q$, and $\eta$. Therefore, they might lead to more or fewer contrails than kerosene fuel. However, as a fuel additive is expected to change the kerosene properties only slightly, it should not result in large changes of $\mathrm{EI}_{\mathrm{H}_{2} \mathrm{O}}, Q$, or $\eta$. Hence, in order to reduce contrail formation, fuel additives must impact the SAc in another way that is independent of the parameter $G$.

The empirical point in the SAc is that water saturation must be reached. It does not follow from thermodynamic principles. The necessity for water saturation owes its existence to the fact that the emitted particles that are responsible for contrail formation (mainly soot) are only poor ice nuclei. If we consider an academic case where the engines instead of soot would emit perfect ice nuclei, contrails would form as soon as the mixture reaches ice saturation (which implies a vapour pressure that is lower than that at water saturation). The empirical fact that contrail formation occurs near water saturation has been tested and confirmed on various research flight campaigns (Busen and Schumann, 1995; IPCC, 1999; Jensen et al., 1998; Kärcher et al., 1998a). It might be possible that fuel additives act to hamper water uptake on the soot particles (for instance by a certain coating that all soot particles would get). This would require higher supersaturation to condense water on the soot particles in the water supersaturated plume, which subsequently freeze to form contrails. This possibility is investigated next.

\section{How additives could affect the SAc}

The maximum ambient temperature at which a contrail can form is that temperature at which the threshold mixing trajectory just touches the water saturation curve. This temperature $T_{\mathrm{ML}}$ is implicitly given by

$\mathrm{d} e_{\mathrm{L}}(T) / \mathrm{d} T=G$,

where $e_{\mathrm{L}}(T)$ is the saturation vapour pressure over liquid water. A fuel additive that would require a certain water saturation ratio $x$ for contrail formation could be described by a similar formula (Mazin and Heymsfield, 1998), namely

$\mathrm{d}\left[x e_{\mathrm{L}}(T)\right] / \mathrm{d} T=G$.

This is equivalent to

$\mathrm{d} e_{\mathrm{L}}(T) / \mathrm{d} T=G / x$, 
which shows that such an effect is also equivalent to a change of the factor $G$. The critical temperature $T_{\mathrm{ML}}$ in ${ }^{\circ} \mathrm{C}$ for any value of $x$ can be approximated with slight change of Eq. (31) in Schumann (1996), viz.:

$$
\begin{aligned}
T_{\mathrm{ML}}= & -46.46+9.43 \ln (G / x-0.053) \\
& +0.720[\ln (G / x-0.053)]^{2} .
\end{aligned}
$$

I have computed $T_{\mathrm{ML}}$ for an $x$-range of 0.5 (about ice saturation) to 2 (which would mean that twice water saturation must be reached for contrail formation), and for $\eta$ in the range from 0.3 to 0.5 (potential value for 2050). The assumed ambient pressure was $220 \mathrm{hPa}$, close to flight level 370 $(37,000 \mathrm{ft}$, or $\sim 10.2 \mathrm{~km}$ altitude). The maximum temperature that would allow contrail formation is shown in Fig. 1.

First, the figure shows that contrails form already at higher temperatures when engines get more efficient. This is a known effect (Schumann, 2000), and has been demonstrated in a well-designed flight experiment (Schumann et al., 2000). Stepping from $\eta=0.3$ to 0.5 increases the maximum temperature for contrail formation by $\sim 4 \mathrm{~K}$, almost independent of $x$. With a typical temperature lapse rate of $8 \mathrm{~K} \mathrm{~km}^{-1}$, this increase means that contrails can form at half a kilometre lower altitude with $\eta=0.5$ than with $\eta=0.3$. Second, as expected, when $x$ is increased above unity, the maximum temperature

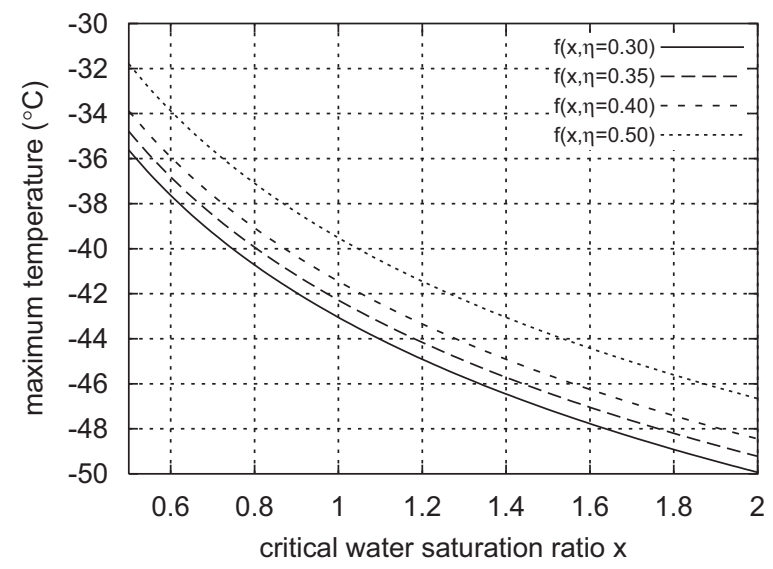

Fig. 1. Maximum temperature that would allow contrail formation as a function of the critical water saturation ratio $x$ that is required for condensation on the exhaust particles. Soot particles as released usually from the current fleet require $x=1$. Different curves refer to different values of the overall propulsion efficiency $\eta$ as indicated in the figure. The calculation has been performed for an ambient pressure of $220 \mathrm{hPa}$ (corresponding approximately to an altitude of $10.2 \mathrm{~km}$ ). for contrail formation decreases. Under the unrealistic assumption that an appropriate additive would lead to $x=2$, the maximum temperature for contrail formation would decrease by $\sim 7 \mathrm{~K}$, corresponding to an altitude increase of about $900 \mathrm{~m}$ (depending on the actual lapse rate). A value of $x \approx 1.4$ would be needed to balance the potential increase in propulsion efficiency until 2050.

\section{Discussion}

The flight experiment conducted by Busen and Schumann (1995) tested the contrail formation properties of kerosenes with different sulphur contents, respectively, on the same research aircraft. Fuel sulphur mass fractions of 2 and $250 \mathrm{ppm}$ did not lead to noticeable differences in contrail onset. A similar experiment (Schumann et al., 1996) with fuel sulphur mass fractions of 170 and $5500 \mathrm{ppm}$, respectively, led to slightly different contrail onset altitudes and temperatures: the contrail from the sulphur richer exhaust formed at $0.2-0.4 \mathrm{~K}$ higher temperature, corresponding to a change in $x$ of $\sim 0.02-0.04$. In other terms, the addition of a very large amount of sulphur beyond allowed jet fuel specifications (ASTM, 1994) only leads to a very slight change of the parameter $x$.

Thus, it is highly questionable whether additives could lead to a complete coating of the soot particles such that $x$ could reach a value of 1.4 or higher. In order to reach such high water supersaturation, the material for the coating would have to be very hydrophobic, characterised by large contact angles. Even pure graphite particles acquire a fraction of a monolayer of water molecules in contrail threshold conditions (Kärcher et al., 1996). The creation of thick oil or fat coatings around soot particles is unlikely to be under technical control given the complexity of jet combustion processes, and such materials may create adverse environmental and health effects.

In the likely case that the additive results in partial coatings of the soot particles, the SAc is not affected at all (i.e. $x$ remains unity), because the uncoated portions of the soot particle surfaces will trigger contrail formation in the usual way. However, it might then be possible that fewer but larger ice crystals form, rendering young contrails optically thinner. This situation would be similar to the case of cryoplanes that do not emit any soot particles. In the absence of soot and sulphur emissions (see also below), contrails still form on 
entrained ambient aerosol particles or on metal particles from the jet engines (Kärcher et al., 1998a). Cryoplane contrails would contain fewer (at least a factor 10) but larger ice crystals than kerosene contrails, hence they would be optically thinner than the latter (Ström and Gierens, 2002). There is some concern that cryoplanes may increase emissions of water vapour into the stratosphere, with consequent adverse effects on climate and ozone chemistry. Cryoplanes have a much larger water emission index, and liquid hydrogen has higher chemical energy content than kerosene, such that cryoplane contrails can form at higher temperatures than kerosene contrails. This does not hold for the kerosene plus additives case with incomplete soot coating; in that case the maximum temperature is not affected, only the contrail optical properties might change.

Regardless, the question remains to what a degree an additive to kerosene fuel can lead to coating of the soot particles such that virtually all of them will condense water vapour significantly above water saturation. Probably it will be very difficult to find such materials, that fulfil at the same time other technical and safety requirements.

The reader may have noticed that I have neglected so far the fact that aircraft engines also nucleate and emit volatile particles. These ultrafine particles consist of aqueous mixtures of sulphuric acid and condensable organics originating from incomplete combustion. Taking these particles into account, we believe that the use of fuel additives to mitigate contrail formation is even less justified.

If soot would be removed completely from jet engine exhaust (or made totally inert by a hydrophobic coating), then a contrail would form on the sulphuric acid droplets (which are at least 10-100 times more abundant than soot particles at emission) via homogeneous freezing at slightly lower temperatures $(<1 \mathrm{~K})$ than on soot particles (Kärcher et al., 1998a). Surprisingly, the properties of young contrails (crystal number density and size) do not change substantially upon removing the soot emissions because of the strong dynamical control (high jet plume cooling rates) of contrail formation. The slight decrease of the threshold temperature of $<1 \mathrm{~K}$ for the latter pathway corresponds to an increase in $x$ of $<0.1$. If additionally, the kerosene would be completely desulphurised, freezing nuclei in similar concentrations are still provided by the condensable organic emissions, possibly formaldehyde and ethene (Kärcher et al., 1998b).

\section{Conclusions}

This paper discusses a potential mitigation option for contrail formation, namely that certain additives to kerosene jet fuel would lead to a coating of the emitted soot particles that makes them much less able to act as condensation nuclei for water vapour. This case can be treated as a simple variation of the thermodynamic SAc for contrail formation. It has been shown that it would be necessary to produce a complete soot coating with a threshold water saturation ratio of about 1.4 (i.e. $40 \%$ supersaturation) for water condensation to decrease the maximum temperature allowing for contrail formation by $4 \mathrm{~K}$. The same $4 \mathrm{~K}$ would be balanced until 2050 by an expected increase of the overall propulsion efficiency to 0.5 . Thus, in order to make a substantial effect, the additive should lead to an even higher threshold supersaturation. It is highly unlikely that this can be achieved, in particular since volatile particles (sulphuric acid and organics) also form ice crystals in aircraft plumes with contributions increasing with decreasing temperature and increasing fuel sulphur content (Kärcher et al., 1998a). Incomplete coating of the soot particles renders the SAc unaffected. Only in case practically all soot particles could be coated with a highly hydrophobic material, the resulting contrails would be optically thinner than today's kerosene contrails. The question remains whether such hydrophobic materials can be used as additives, and whether they are technologically feasible and environmentally friendly.

Fuel additives might help alter contrail optical properties to a certain degree, and may also have other beneficial effects (in particular for the engines). However, as I have demonstrated, they are not useful for contrail suppression. For the near future, I, therefore recommend to rather strive for the flexible operational measures as a more promising contrail mitigation option. Indeed, investigations for environmentally compatible flight routing are now underway within a project (http:// www.pa.op.dlr.de/ufo/) under the German climate protection programme.

\section{Acknowledgements}

This work has been stimulated by discussions with Thrassos Panidis, Kyriakos Papailiou, and Chris Wilson on occasion of a workshop on Aeroengine Emissions, Plume Processes, and Contrail Cirrus on 
7-8 November 2005 in Athens. The workshop was held within the framework of the European Network of Excellence Environmentally Compatible Air Transport System (ECATS) Project no. ANE-CT2005-012284). I thank in particular Ulrich Schumann for valuable comments on a first draft of the manuscript, and Bernd Kärcher for providing additional insight for the revised version.

\section{References}

ASTM, 1994. Standard specification for aviation fuels, D 165593a, Annual Book of ASTM Standards, 05.0, American Society for Testing and Materials, Philadelphia, PA 191031187, p. $555-563$.

Busen, R., Schumann, U., 1995. Visible contrail formation from fuels with different sulfur contents. Geophysical Research Letters 22, 1357-1360.

Fichter, C., Marquart, S., Sausen, R., Lee, D.S., Norman, P.D., 2004. Impact of cruise altitude on contrails. In: Sausen, R., Fichter, C., Amanatidis, G. (Eds.), Aviation, Atmosphere and Climate. Proceedings of a European Conference, European Commission, Air Pollution Research Report 83. Brussels, pp. 322-327.

Gierens, K., Sausen, R., Schumann, U., 1999. A diagnostic study of the global distribution of contrails, Part II. Future traffic scenarios. Theoretical and Applied Climatology 63, 1-9.

IPCC, 1999. Aviation and the Global Atmosphere. In: Penner, J.E., Lister, D.H., Griggs, D.J., Dokken, D.J., McFarland, M. (Eds.). Cambridge University Press.

Jensen, E.J., Toon, O.B., Kinne, S., Sachse, G.W., Anderson, B.E., Chan, K.R., Twohy, C., Gandrud, B., Heymsfield, A., Miake-Lye, R.C., 1998. Environmental conditions required for contrail formation and persistence. Journal of Geophysical Research 103, 3929-3936.

Kärcher, B., Peter, T., Biermann, U.M., Schumann, U., 1996. The initial composition of jet condensation trails. Journal of the Atmospheric Sciences 53, 3066-3083.

Kärcher, B., Busen, R., Petzold, A., Schröder, F.P., Schumann, U., Jensen, E.J., 1998a. Physicochemistry of aircraft-generated liquid aerosols, soot, and ice particles. 2. Comparison with observations and sensitivity studies. Journal of Geophysical Research 103, 17129-17148.

Kärcher, B., Yu, F., Schröder, F.P., Turco, R.P., 1998b. Ultrafine aerosol particles in aircraft plumes: analysis of growth mechanisms. Geophysical Research Letters 25, 2793-2796.

Mannstein, H., Schumann, U., 2005. Aircraft induced contrail cirrus over Europe. Meteorologische Zeitschrift 14, 549-554.

Mannstein, H., Spichtinger, P., Gierens, K., 2005. A note on how to avoid contrail cirrus. Transportation Research Part D 10, 421-426.
Marquart, S., Ponater, M., Mager, F., Sausen, R., 2003. Future development of contrail cover, optical depth and radiative forcing: impacts of increasing air traffic and climate change. Journal of Climate 16, 2890-2904.

Marquart, S., Ponater, M., Ström, L., Gierens, K., 2005. An upgraded estimate of the radiative forcing of cryoplane contrails. Meteorologische Zeitschrift 14, 573-582.

Mazin, I.P., Heymsfield, A., 1998. The theory of contrails. Russian Meteorology and Hydrology 9, 1-8.

Noland, R.B., Williams, V., Toumi, R., 2004. Policies for mitigating contrail formation from aircraft. In: Sausen, R., Fichter, C., Amanatidis, G. (Eds.), Aviation, Atmosphere and Climate. Proceedings of a European Conference, European Commission, Air Pollution Research Report 83. Brussels, pp. 328-333.

Ponater, M., Pechtl, S., Sausen, R., Schumann, U., Hüttig, G., 2006. Potential of the cryoplane technology to reduce aircraft climate impact: a state-of-the-art assessment. Atmospheric Environment 40, 6928-6944.

Sausen, R., Isaksen, I., Grewe, V., Hauglustaine, D., Lee, D.S., Myhre, G., Köhler, M.O., Pitari, G., Schumann, U., Stordal, F., Zerefos, C., 2005. Aviation radiative forcing in 2000: an update of IPCC (1999). Meteorologische Zeitschrift 14, 555-561.

Schumann, U., 1996. On conditions for contrail formation from aircraft exhausts. Meteorologische Zeitschrift 5, 4-23.

Schumann, U., 2000. Influence of propulsion efficiency on contrail formation. Aerospace Science and Technology 4, 391-401.

Schumann, U., 2005. Formation, properties and climatic effects of contrails. Comptes Rendus Physique 6, 549-565.

Schumann, U., Ström, J., Busen, R., Baumann, R., Gierens, K., Krautstrunk, M., Schröder, F.P., Stingl, J., 1996. In situ observations of particles in jet aircraft exhausts and contrails for different sulfur-containing fuels. Journal of Geophysical Research 101, 6853-6869.

Schumann, U., Busen, R., Plohr, M., 2000. Experimental test of the influence of propulsion efficiency on contrail formation. Journal of Aircraft 37, 1083-1087.

Ström, L., Gierens, K., 2002. First simulations of cryoplane contrails. Journal of Geophysical Research, 107.

Stuber, N., Forster, P., Rädel, G., Shine, K., 2006. The importance of the diurnal and annual cycle of air traffic for contrail radiative forcing. Nature 441, 864-867.

Williams, V., Noland, R.B., 2005. Variability of contrail formation conditions and the implications for policies to reduce the climate impacts of aviation. Transportation Research Part D 10, 269-280.

Williams, V., Noland, R.B., Toumi, R., 2002. Reducing the climate change impacts of aviation by restricting cruise altitudes. Transportation Research Part D 7, $451-464$. 